\title{
Synthesis, FTIR and Electronic Spectra Studies of Metal (II) Complexes of Acethydrazide Derivative
}

Nzikayel S, Akpan IJ* and Adams EC

Department of Chemistry, Faculty of Science, University of Uyo, Nigeria

\begin{abstract}
Acethydrazide was modified by addition of benzaldehyde refluxing in ethanol to obtain a new product: N'Benzylideneacethydrazide. The new product obtained was complexed with Iron (II) and Copper (II) salt. The result of the FT-IR analysis of acethydrazide, N'-Benzylideneacethydrazide and its complexes were compared to ascertain the possible points and mode of coordination to the metal (II) centre. The shift in the absorption band of the N'-Benzylideneacethydrazide (N'-BA) from $3337 \mathrm{~cm}-1(\mathrm{~N}-\mathrm{H})$ to $3462 \mathrm{~cm}-1$ and $3406 \mathrm{~cm}-1(\mathrm{~N}-\mathrm{H})$ in the spectra of the $\mathrm{Fe}(\mathrm{II})$ and $\mathrm{Cu}(\mathrm{II})$ complexes respectively, indicates the coordination of the N'-Benzylideneacethydrazide to the metal ion via $\mathrm{O}$ and $\mathrm{N}$ atoms of the carbonyl and amide functional groups. The products were further characterized by UV/Visible spectroscopic technique and other physical measurements like melting point and solubility test.
\end{abstract}

Keywords: Acethydrazide; Ligand; Metal-complex; N'Benzylideneacethydrazide; Infrared spectroscopy; Ultraviolet visible spectroscopy

\section{Introduction}

Acethydrazide belongs to the hydrazine/hydrazone group which plays an important role for the anti-microbial activity. Recently, Acethydrazide has gained great importance due to the anti-tuberculosis activity it possesses [1]. A disease caused by parasites represents a major world health problem with very limited therapeutic options.

Most of the available treatments are limited in their efficacies as a result of being decades old and are suffering from limited efficacy and/ or undesirable side effects. The efficacy of therapeutic agent is known to be enhanced upon coordination to metal ion [2]. Metal ions are electron deficient whereas most biological molecule drugs are electron rich. The attraction between these opposite charges leads to a general tendency for metal ions to bind and interact with biological molecules [3].

To the best of our knowledge, this represents the first Synthesis, FTIR, and electronic spectra studies of metal(II) complexes of Acethydrazide and Pyrazine-2-carboxylic acid derivatives.

\section{Materials and Methods}

\section{Materials}

All reagents and chemicals were of analytical grade obtained from commercial sources and were not further purified. Acethydrazide (98\%) and ethanol (98\%) were obtained Sigma Aldrich (UK), benzaldehyde (96\%) was obtained from Fisher scientific, UK. Hydrated metal salts: $\left(\mathrm{CuSO}_{4} .5 \mathrm{H}_{2} \mathrm{O}\right),\left(\mathrm{FeSO}_{4} \cdot 7 \mathrm{H}_{2} \mathrm{O}\right)$ used for complexation were obtained from British Drug House (BDH) Poole, England. UV-Visible spectra were recorded on a Jenway $7305 \mathrm{UV}$-Vis spectrophotometer and FTIR spectra were recorded on a Shimadzu scientific model $8400 \mathrm{~S}$ IR Prestige 21 spectrophotometer with $\mathrm{KBr}$ pellets.

\section{Synthesis of N'-Benzylideneacethydrazide (N'-BA)}

Three (3) $\mathrm{mmol}(0.222 \mathrm{~g}$ ) of acethydrazide was dissolved in $10 \mathrm{ml}$ of ethanol; $5 \mathrm{ml}$ of benzaldehyde was added and refluxed for 4 hours with stirring. The resulting solution was a wine colour and was cooled at room temperature and allowed to stand for 5 days without disruption. The resulting solution was then concentrated for 10 minutes using a hot plate and then allowed to cool at room temperature. Colourless rod-like crystals were formed on cooling at room temperature.

\section{Synthesis of $\left[\mathrm{FeSO}_{4}\left(\mathrm{~N}^{\prime}-\mathrm{BA}\right)\right] \cdot 7 \mathrm{H}_{2} \mathrm{O}$}

One (1) $\mathrm{mmol}(0.278 \mathrm{~g})$ of Iron (II) sulphateheptahydrate was dissolved in $10 \mathrm{ml}$ solvent system (Ethanol 1:1 deionised water) and the $0.6 \mathrm{mmol}(0.099 \mathrm{~g})$ of N'-Benzylideneacethydrazide (N'-BA) was added slowly while stirring. On heating it dissolved completely giving a yellow colouration and on cooling it settles and a precipitate formed. It was filtered and dried in a dessicator, well-shaped green/brown crystals was obtained.

Equation of Reaction: $\mathrm{FeSO}_{4} \cdot 7 \mathrm{H}_{2} \mathrm{O}+\mathrm{N}^{\prime}-\mathrm{BA} \rightarrow\left[\mathrm{FeSO}_{4}\left(\mathrm{~N}^{\prime}-\mathrm{BA}\right)\right] .7 \mathrm{H}_{2} \mathrm{O}$ Synthesis of $\left[\mathrm{CuSO}_{4}\left(\mathrm{~N}^{\prime}-\mathrm{BA}\right)\right] .5 \mathrm{H}_{2} \mathrm{O}$

One (1) mmol (0.249 g) of Copper (II) sulphatepentahydrate was dissolved in $10 \mathrm{ml}$ solvent system (Ethanol 1:1 deionised water) and the $0.6 \mathrm{mmol}(0.099 \mathrm{~g})$ of N'- benzylideneacethydrazide (N'-BA) was added slowly while stirring. On heating it dissolved completely giving a deep green colouration and on cooling it settles and a deep blue precipitate formed. It was filtered and dried in a dessicator. A pale blue crystal well shaped was obtained.

Equation of Reaction: $\mathrm{CuSO}_{4} \cdot 5 \mathrm{H}_{2} \mathrm{O}+\mathrm{N}^{\prime}-\mathrm{BA} \rightarrow\left[\mathrm{CuSO}_{4}\left(\mathrm{~N}^{\prime}-\right.\right.$ BA) $] .5 \mathrm{H}_{2} \mathrm{O}$

\section{Results and Discussion}

Some physical and spectroscopic data of the ligand and its metal complexes are presented in Table 1 . The complexes showed a melting point value and $\mathrm{N}^{\prime}$ - Benzylideneacethydrazide (N'-BA) showed a low

*Corresponding author: Akpan IJ, Department of Chemistry, Faculty of Science, University of Uyo, Nigeria, Tel: +2348163319802; E-mail: isaacakpan@yahoo.com

Received February 12, 2018; Accepted February 15, 2018; Published February 20, 2018

Citation: Nzikayel S, Akpan IJ, Adams EC (2018) Synthesis, FTIR and Electronic Spectra Studies of Metal (II) Complexes of Acethydrazide Derivative. Med Chem (Los Angeles) 8: 026-028. doi: 10.4172/2161-0444.1000493

Copyright: ( 2018 Nzikayel S, et al. This is an open-access article distributed under the terms of the Creative Commons Attribution License, which permits unrestricted use, distribution, and reproduction in any medium, provided the original author and source are credited. 
melting point when compared together. The two complexes synthesized were crystalline in nature. Solubility of N'-Benzylideneacethydrazide (N'-BA) and the complexes are presented in Table 2.

\section{Infrared spectra of $\mathrm{N}^{\prime}-$ Benzylideneacethydrazide (N'-BA) and metal complexes}

A comparative study of the IR Spectra data of N'Benzylideneacethydrazide (N'-BA) and $\mathrm{Fe}(\mathrm{II}) / \mathrm{Cu}(\mathrm{II})$ complexes measured from 400 to $4000 \mathrm{~cm}^{-1}$. The important Infrared group frequencies of ( $\left.\mathrm{N}^{\prime}-\mathrm{BA}\right)$ and $\mathrm{Fe}(\mathrm{II}) / \mathrm{Cu}$ (II) complexes are given in Table 3 . The spectra of the ligands and complexes exhibit strong absorption bands in the range of $3229-3462 \mathrm{~cm}^{-1}$ assigned to $v(\mathrm{~N}-\mathrm{H})$ vibrations [4]. The band at $\left(3337 \mathrm{~cm}^{-1}, 3229 \mathrm{~cm}^{-1}\right)$ in the spectrum of $\left(\mathrm{N}^{\prime}-\mathrm{BA}\right)$ is attributed to $\boldsymbol{v}(\mathrm{NH})$ of the amide group but when compared to $\mathrm{Fe}(\mathrm{II}) / \mathrm{Cu}(\mathrm{II})$ complexes, there was a shift in the frequency of $\mathrm{Fe}(\mathrm{II}) /$ $\mathrm{Cu}(\mathrm{II})$ complexes : $\left(3462 \mathrm{~cm}^{-1}, 3385 \mathrm{~cm}^{-1}\right)$ and $3406 \mathrm{~cm}^{-1}$ respectively to a higher frequency in the region of the $\boldsymbol{v}(\mathrm{NH})$. For the spectrum of N'- Benzylideneacethydrazide, a weak and sharp band occurs at $1609 \mathrm{~cm}^{-1}$ which is assigned to $\mathrm{C}=\mathrm{N}$ stretching different from the $1655 \mathrm{~cm}^{-1}$ and $1547 \mathrm{~cm}^{-1}$ bands of $\mathrm{Fe}(\mathrm{II}) / \mathrm{Cu}$ (II) complex respectively. The characteristic absorption bands in the region 1680-1630 $\mathrm{cm}^{-1}$ is assigned to the carbonyl group of an amide [5]. The sharp absorption band of $\mathrm{C}=\mathrm{O}$ stretching observed at $1655 \mathrm{~cm}^{-1}$ of $\mathrm{N}^{\prime}$ Benzylideneacethydrazide shifted to a lower frequency in the $\mathrm{Fe}(\mathrm{II})$ $\left(1622 \mathrm{~cm}^{-1}\right),\left(1622 \mathrm{~cm}^{-1}\right)$ complex. The C-H stretch observed at 3044 $\mathrm{cm}^{-1}$ of $\mathrm{N}^{\prime}$-Benzylideneacethydrazide shows a slight shift in lower frequency of the $\mathrm{Fe}(\mathrm{II})$ complex having $3258 \mathrm{~cm}^{-1}$ with exception to $\mathrm{Cu}$ (II) complex. The bands at $507 \mathrm{~cm}^{-1}$ and $517 \mathrm{~cm}^{-1}$ of the $\mathrm{Fe}$ (II)/Cu(II) complexes are attributed to the $\mathrm{Fe}-\mathrm{N}, \mathrm{Cu}-\mathrm{N}$ respectively also the bands at $615 \mathrm{~cm}^{-1}$ and $\left(660 \mathrm{~cm}^{-1}, 604 \mathrm{~cm}^{-1}\right)$ of the $\mathrm{Fe}(\mathrm{II}) / \mathrm{Cu}(\mathrm{II})$ complexes are attributed to the $\mathrm{Fe}-\mathrm{O}, \mathrm{Cu}-\mathrm{O}$ respectively.

In the UV/Visible region of the $\left[\mathrm{FeSO}_{4}\left(\mathrm{~N}^{\prime}-\mathrm{BA}\right)\right] \cdot 7 \mathrm{H}_{2} \mathrm{O}$ complex (Figure 1), two peaks were observed at $320 \mathrm{~nm}$ and $420 \mathrm{~nm}$ which are due to charge transition from ligands to metal and d-d transition respectively. The $\left[\mathrm{CuSO}_{4}\left(\mathrm{~N}^{\prime}-\mathrm{BA}\right)\right] \cdot 5 \mathrm{H}_{2} \mathrm{O}$ complex (Figure 2 ) showed one sharp and broad peaks at $310 \mathrm{~nm}$ and $750 \mathrm{~nm}$ which are also due to charge transition from ligands to metal and $\mathrm{d}-\mathrm{d}$ transition respectively (Table 4).

\section{Conclusion}

The proposed molecular structure of the compound N'Benzylideneacethydrazide ( $\left.\mathrm{N}^{\prime}-\mathrm{BA}\right)$ was achieved through refluxing method and there was a functional group transformation. From the interpretation of the UV/Visible spectroscopy and FT-IR spectrum of N'-Benzylideneacethydrazide and $\mathrm{Fe}(\mathrm{II}) / \mathrm{Cu}(\mathrm{II})$ complexes, the analysis indicates the co-ordination of the oxygen of the carbonyl group to the metal ion, co-ordination of the amide nitrogen to the metal ion, also the co-ordination of the oxygen of the sulphate ion.

\begin{tabular}{|c|c|c|c|}
\hline Compound & Physical state & Melting point & Colour \\
\hline $\mathbf{N}^{\prime}-\mathrm{BA}$ & Crystalline & $94.1^{\circ} \mathrm{C}$ & Colourless \\
\hline$\left[\mathrm{FeSO}_{4}\left(\mathrm{~N}^{\prime}-\mathrm{BA}\right)\right] .7 \mathrm{H}_{2} \mathrm{O}$ & Crystalline & $106^{\circ} \mathrm{C}$ & Green/Brown \\
\hline$\left[\mathrm{CuSO}_{4}\left(\mathrm{~N}^{\prime}-\mathrm{BA}\right)\right] \cdot 5 \mathrm{H}_{2} \mathrm{O}$ & Crystalline & $163^{\circ} \mathrm{C}$ & Pale Blue \\
\hline
\end{tabular}

Table 1: Physical properties of $\mathrm{N}^{\prime}-\mathrm{BA}$ and $\mathrm{Fe}(\mathrm{II}) / \mathrm{Cu}(\mathrm{II})$ complexes.

\begin{tabular}{|c|c|c|c|c|c|c|c|c|}
\hline \multirow{2}{*}{ Compound } & \multicolumn{2}{|c|}{ Deionized Water } & \multicolumn{2}{|c|}{ Ethanol } & \multicolumn{2}{|c|}{ Methanol } & \multicolumn{2}{|c|}{ Acetone } \\
\hline & Cold & RT & Cold & RT & Cold & RT & Cold & RT \\
\hline $\begin{array}{c}\mathrm{N}^{\prime}-\mathrm{BA} \\
{\left[\mathrm{FeSO}_{4}\left(\mathrm{~N}^{\prime}-\mathrm{BA}\right)\right] \cdot 7 \mathrm{H}_{2} \mathrm{O}}\end{array}$ & $\begin{array}{l}\text { SS } \\
\text { S }\end{array}$ & $\begin{array}{c}\text { SS } \\
\text { S }\end{array}$ & $\begin{array}{c}\text { S } \\
\text { SS }\end{array}$ & $\begin{array}{c}\text { S } \\
\text { SS }\end{array}$ & $\begin{array}{c}\text { S } \\
\text { INS }\end{array}$ & $\begin{array}{l}S \\
S\end{array}$ & $\begin{array}{c}\text { S } \\
\text { SS }\end{array}$ & $\begin{array}{l}\text { S } \\
\text { SS }\end{array}$ \\
\hline$\left[\mathrm{CuSO}_{4}\left(\mathrm{~N}^{\prime}-\mathrm{BA}\right)\right] \cdot 5 \mathrm{H}_{2} \mathrm{O}$ & ss & $\mathrm{s}$ & SS & ss & ss & SS & INS & INS \\
\hline
\end{tabular}

S=Soluble; $S S=$ Sparingly Soluble; INS=Insoluble; RT=Room temperature

Table 2: Solubility of ligand and metal complexes in different solvents.

\begin{tabular}{|c|c|c|c|c|c|c|c|c|c|}
\hline \multirow{2}{*}{ Ligands/Complex } & \multicolumn{9}{|c|}{ Assignment $\left(\mathbf{c m}^{-1}\right)$} \\
\hline & $\mathrm{U}(\mathrm{N}-\mathrm{H})$ & $\mathrm{U}(=\mathrm{C}-\mathrm{H})$ & $u(C=0)$ & $u(C=N)$ & u(C-H) & $u(C-O)$ & $\mathrm{U}(-\mathrm{N}=\mathrm{N})$ & $\mathrm{U}(\mathrm{M}-\mathrm{N})$ & $\mathrm{U}(\mathrm{M}-\mathrm{O})$ \\
\hline Acethydrazide & $\begin{array}{l}3453 \\
\mathrm{br}, \mathrm{S} \\
3266 \\
\mathrm{br}, \mathrm{S}\end{array}$ & $3038 \mathrm{br}, \mathrm{S}$ & $1663 \mathrm{br}, \mathrm{S}$ & -------- & $\begin{array}{l}2938 \\
2853\end{array}$ & -------- & --------- & & ------ \\
\hline $\begin{array}{l}\text { N'- Benzylideneacethydrazide (N'- } \\
\text { BA) }\end{array}$ & $\begin{array}{l}3337 \\
\text { br, w } \\
3229 \\
\text { Sh, S }\end{array}$ & 3044 Sh, m & $1655 \mathrm{Sh}, \mathrm{w}$ & 1609 Sh, w & $\begin{array}{l}2843 \mathrm{br}, \mathrm{w} \\
2726 \mathrm{br}, \mathrm{w}\end{array}$ & ----- & 1699 Sh, S & 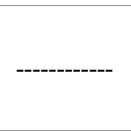 & ------ \\
\hline$\left[\mathrm{FeSO}_{4}\left(\mathrm{~N}^{\prime}-\mathrm{BA}\right)\right] \cdot 7 \mathrm{H}_{2} \mathrm{O}$ Complex & $\begin{array}{l}3462 \\
\text { br, S } \\
3385 \\
\text { br, S }\end{array}$ & $3258 \mathrm{br}, \mathrm{S}$ & $1622 \mathrm{Sh}, \mathrm{w}$ & 1655 Sh, w & ------- & $1111 \mathrm{br}, \mathrm{S}$ & ------- & $507 \mathrm{br}, \mathrm{w}$ & $615 \mathrm{Sh}, \mathrm{S}$ \\
\hline$\left[\mathrm{CuSO}_{4}\left(\mathrm{~N}^{\prime}-\mathrm{BA}\right)\right] \cdot 5 \mathrm{H}_{2} \mathrm{O}$ Complex & $\begin{array}{l}3406 \\
b r, S\end{array}$ & 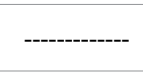 & $1622 \mathrm{br}, \mathrm{w}$ & $1547 \mathrm{br}, \mathrm{w}$ & ------- & $1155 \mathrm{br}, \mathrm{S}$ & ------ & 517 Sh, w & $660 \mathrm{br}, \mathrm{m}$ \\
\hline
\end{tabular}

Key: br=broad, $\mathrm{Sh}=\mathrm{Sharp}, \mathrm{S}=\mathrm{Strong}, \mathrm{m}=$ medium, $\mathrm{w}=$ weak

Table 3: Selected FTIR absorption bands for Acethydrazide, N'-Benzylideneacethydrazide(N'-BA) and Fe(II)/Cu(II) complexes. 
Citation: Nzikayel S, Akpan IJ, Adams EC (2018) Synthesis, FTIR and Electronic Spectra Studies of Metal (II) Complexes of Acethydrazide Derivative. Med Chem (Los Angeles) 8: 026-028. doi: 10.4172/2161-0444.1000493

\begin{tabular}{|c|c|c|c|}
\hline Compound & Absorbance Maximum & $\begin{array}{c}\text { Wavelength } \\
\lambda_{\max }(\mathrm{nm})\end{array}$ & Assignment \\
\hline$\left[\mathrm{FeSO}_{4}\left(\mathrm{~N}^{\prime}-\mathrm{BA}\right)\right] \cdot 7 \mathrm{H}_{2} \mathrm{O}$ & $\begin{array}{l}3.000 \\
3.000\end{array}$ & $\begin{array}{l}320 \\
420\end{array}$ & $\begin{array}{c}\text { C-T Band } \\
\text { d-d Transition }\end{array}$ \\
\hline$\left[\mathrm{CuSO}_{4}\left(\mathrm{~N}^{\prime}-\mathrm{BA}\right)\right] \cdot 5 \mathrm{H}_{2} \mathrm{O}$ & $\begin{array}{l}3.000 \\
0.222\end{array}$ & $\begin{array}{l}310 \\
750\end{array}$ & $\begin{array}{c}\text { C-T Band } \\
\text { d-d Transition }\end{array}$ \\
\hline
\end{tabular}

$\mathrm{C}-\mathrm{T}=$ Charge transition

Table 4: Electronic spectra data on UV/Vis spectrophotometry.

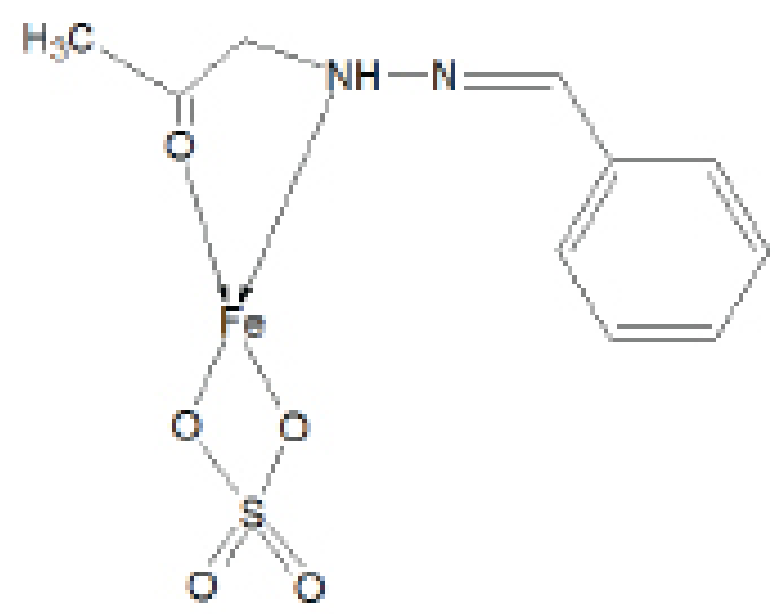

Figure 1: Proposed Structure of $\left[\mathrm{FeSO}_{4}\left(\mathrm{~N}^{\prime}-\mathrm{BA}\right)\right] \cdot 7 \mathrm{H}_{2} \mathrm{O}$ complex.

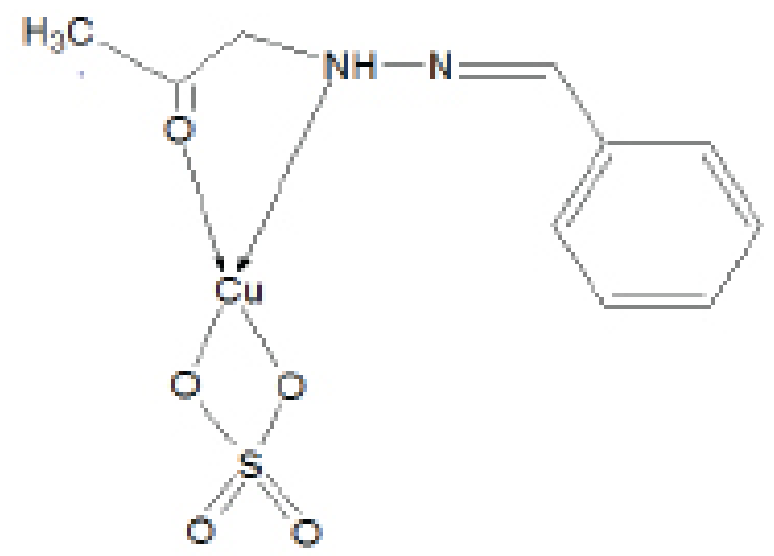

Figure 2: Proposed Structure of $\left[\mathrm{CuSO}_{4}\left(\mathrm{~N}^{\prime}-\mathrm{BA}\right)\right] \cdot 5 \mathrm{H}_{2} \mathrm{O}$ complex.

\section{References}

1. Loncle C, Brunel JM, Vidal N, Dherbomez M, Letourneux Y (2004) Synthesis and Antifungal Activity of cholesterol-Hydrazone Derivatives. European Journal of Medicinal Chemistry 39: 1067-1071.

2. Obaleye JA, Nde-Aga JB, Balogun EA (1997) Some antimalaria drug metal complexes: Synthesis, characterization and their in vivo evaluation against malaria parasite. Afr J Sci 1: 10-12.

3. Obaleye JA, Caira MR, Tella AC (2009) Synthesis, characterization and crystal structures of the tetrachlorocuprate and tetrabromocadmate salts of the antimalarial mefloquine. Structural Chemistry 20: 859-868.

4. Bellamy LJ (1980) Advances in Infrared Group Frequencies. Infrared Spectra of Complex Molecule. Chapman and Hall, New York, Vol. 2.

5. Coates JP (1996) The interpretation of infrared spectra: Published reference sources. Applied Spectroscopy Rev 31: 179-192. 